\title{
Comparative study of ecohydrological streamflow probability distributions
}

\author{
Serena Ceola, ${ }^{1}$ Gianluca Botter, ${ }^{2}$ Enrico Bertuzzo, ${ }^{1}$ Amilcare Porporato, ${ }^{3}$ \\ Ignacio Rodriguez-Iturbe, ${ }^{4}$ and Andrea Rinaldo ${ }^{1,2}$ \\ Received 12 January 2010; revised 31 March 2010; accepted 15 April 2010; published 1 September 2010.
}

[1] We run a comparative study of ecohydrological models of streamflow probability distributions (pdfs), $p(Q)$, derived by Botter et al. (2007a, 2009), against field data gathered in different hydrological contexts. Streamflows measured in several catchments across various climatic regions of northeastern Italy and the United States are employed. The relevance of the work stems from the implied analytical predictive ability of hydrologic variability, whose role on stream and riparian ecological processes and large-scale management schemes is fundamental. The tools employed are analytical models of $p(Q)$ (and of the related flow duration curve, $D(Q)$ ) derived by coupling suitable storage-discharge relations with a stochastic description of streamflow production through soil moisture dynamics, and are expressed as a function of few macroscopic rainfall, soil, vegetation and geomorphological parameters. In this work we compare the performances of a recent version of the model (which includes the effects of nonlinear subsurface storage-discharge relations) to those provided by the linear version through the application of the models to 13 test catchments belonging to various climatic and geomorphic contexts. A general agreement between predicted and observed daily streamflows pdfs is shown, though differences emerge between the linear and the nonlinear approaches. In particular, by including the effects of a nonlinear storage-discharge relation the model accuracy is shown to increase with respect to the linear scheme in most examined cases. We show that this is not simply attributable to the added parameter but corresponds to a proper likelihood increase. The nonlinear model is shown to exhibit three basic forms for $p(Q)$ (monotonically decreasing with an atom of probability in $Q=0$, bell-shaped with the mode close to zero, bell-shaped with the mode close to the mean), corresponding to different hydrologic regimes which are clearly detectable in field data. Inferences on the nonlinear character of the relation between subsurface storage and discharge from observed $p(Q)$ are finally drawn.

Citation: Ceola, S., G. Botter, E. Bertuzzo, A. Porporato, I. Rodriguez-Iturbe, and A. Rinaldo (2010), Comparative study of ecohydrological streamflow probability distributions, Water Resour. Res., 46, W09502, doi:10.1029/2010WR009102.

\section{Introduction}

[2] A comprehensive probabilistic characterization of streamflow variability in river basins has noteworthy scientific and social implications due to the relevant impacts on in-stream biogeochemical processes, human exploitations of stream water and ecological services of riparian and riverine environments. Streamflows at the closure of a whole river basin are the outcome of many intertwined ecohydrological and climatic processes, such as infiltration from rainfall,

\footnotetext{
${ }^{1}$ Laboratory of Ecohydrology, Ecole Polytechnique Fédérale, Lausanne, Switzerland.

${ }^{2}$ Dipartimento di Ingegneria Idraulica, Marittima, Ambientale e Geotecnica, Università di Padova, Padua, Italy.

${ }^{3}$ Department of Civil and Environmental Engineering, Duke University, Durham, North Carolina, USA.

${ }^{4}$ Department of Civil and Environmental Engineering, Princeton University, Princeton, New Jersey, USA.
}

Copyright 2010 by the American Geophysical Union 0043-1397/10/2010WR009102 evapotranspiration and recharge from landscape-scale processes related to meteorological and land surface physical and vegetative conditions, runoff production and transport dynamics occurring in channeled and unchanneled regions of the basin [e.g., Chow, 1964; Chow et al., 1988; Rinaldo et al., 1991; Vogel and Fennessey, 1994; Rodriguez-Iturbe and Rinaldo, 1997; Brutsaert and Lopez, 1998; Jothityangkoon et al., 2001; Eng and Milly, 2007; Magruder et al., 2009]. The intrinsic temporal fluctuations of streamflows, which are now recognized as the key element of natural riverine systems, reflect the stochastic nature of all such underlying processes, and in particular the random intermittence of the rainfall forcing.

[3] Botter et al. [2007a, 2007b, 2007c, 2008, 2009, 2010] have recently analyzed the linkages existing between stochastic streamflow fluctuations and the relevant soil moisture dynamics at catchment scales which, coupled to suitable subsurface storage-discharge relations, provide a general probabilistic model of streamflow dynamics. Analytical formulations were provided of the steady state probability distribution function (pdf) of base flow contributions to 
streamflow, as a function of a few macroscopic rainfall, soil, vegetation and geomorphological parameters. In that context, and throughout this paper, reference is made to streamflows as the subsurface contributions to river discharge that may be seen as the byproduct of soil moisture dynamics, thereby excluding the contributions bypassing it as, say, surface runoff.

[4] The earlier version of the model [Botter et al., 2007a, 2008] postulated a linear storage-discharge relation in subsurface states, which is equivalent to assume exponential recession curves, an assumption with distinguished service in engineering practice [see, e.g., Chow et al., 1988; Beven, 2001; Brutsaert, 2005]. The starting point for our analysis is thus the analytical characterization of the probability distribution function of streamflows achieved therein. Nonlinear storage-discharge relations (which imply power law type streamflow recessions) have recently been incorporated providing novel analytical solutions [Botter et al., 2009]. Nonlinearities in the storage-discharge relation are seen as the byproduct of several factors, among which we recall the decrease of the connectivity of the regions contributing to streamflow (which determines a corresponding increase of the drainage resistance during recessions) and the decrease of hydraulic conductivity with depth in subsurface formations [Van de Griend et al., 2002]. Such nonlinearities have long been studied in the context of hydrological modeling [e.g., Amorocho and Orlob, 1961; Amorocho, 1963, 1967; Porporato and Ridolfi, 2003; Brutsaert, 2005; Kirchner, 2009], and validated in various observational contexts [Brutsaert and Nieber, 1977; Wittenberg, 1999; Mishra et al., 2003; Lee, 2007; Rocha et al., 2007]. Incorporating the effects of nonlinear recessions on the streamflow regime within an analytical stochastic framework provides tools of broad applicability through which interactions among hydrologic, climatic, and geomorphic properties can be explicitly analyzed.

[5] This paper deals with an extensive comparative multisite analysis of the performances of linear and nonlinear schemes against observational data. In particular we propose here an observational validation centered on the comparison of theoretical probability distributions $p(Q)$, and the related flow duration curves $D(Q)$, predicted by the nonlinear approach against statistics of daily streamflows in several catchments across various climatic regimes in northeastern Italy and United States. Different procedures for parameters estimation are compared to identify the best performing one. Moreover, we extend the testing of the linear model using the above data set (a subset of which was previously used [Botter et al., 2007c]). A simultaneous analysis of linear and nonlinear models to a wide data set is crucial to fairly assess the performances, the limits and the validity of the related models. The comparison is also aimed to assess whether, discounting the effect of a different number of parameters, the nonlinear model provides a better description of the hydrologic regime. The work also focuses on a novel approach to characterize nonlinearities between subsurface storage and discharge based on a best-fit procedure of analytical to observed probability distributions of streamflows rather than by traditional methods, say employing recession plots.

[6] The paper is organized as follows. Section 2 reviews the modeling scheme to derive exact probability distribution functions of streamflows, it also presents the catchments investigated and illustrates the estimate procedures of the model parameters on the basis of hydrologic and geomorphologic information. Section 3 presents a comparison of the linear and nonlinear versions of the model against observed streamflow pdfs and flow duration curves. Along the way, we discuss how to describe the possible key nonlinearity between subsurface storage and discharge through the analysis of flow recession curves, and through a novel scheme matching the theoretical and empirical probability distributions of streamflows.

\section{Materials and Methods}

\subsection{Probabilistic Characterization of Streamflows}

[7] The basic tool used in the paper is the analytical characterization of the probability distribution function (pdf) of the slow, subsurface contribution to streamflows on the basis of a stochastic description of soil moisture dynamics in the surface soil layer derived by Botter et al. [2007a, 2007b, 2007c, 2008, 2009]. This section briefly reviews the modeling schemes, which allow a linkage between the probabilistic structure of streamflows and the underlying ecohydrological, climate, and transport processes in vegetated catchments. Note that due to the annual variability of the above mentioned processes, we focus on seasonal pdfs of streamflows by considering 3-month periods during which all the rainfall, soil, vegetation, and geomorphological parameters involved are assumed to be constant.

[8] Following Rodriguez-Iturbe et al. [1999] and RodriguezIturbe and Porporato [2004], rainfall is modeled, at daily timescales, as a zero-dimensional Poisson process with average frequency $\lambda_{P}\left[T^{-1}\right]$, while daily rainfall depths are assumed to be exponentially distributed with parameter $\gamma_{P}\left[L^{-1}\right]$. The first assumption implicitly postulates catchment sizes, say $A$, smaller than the spatial correlation scales of rainfall events and timescales of the process of interest greater than the characteristic duration of single rainfall events (i.e., daily timescales). The relevant ecohydrological processes occurring in the active soil layer, where competition between deep percolation and evapotranspiration processes takes place, are described in a lumped approach which uses constant parameters to define the storage capacity of the relevant control volume: the root zone depth (i.e., the depth of the active soil layer), $Z_{r}[L]$, and its porosity, $n$. The temporal evolution of spatially-averaged relative soil moisture in the root zone, $s(t)$, is thus seen as the result of the following three processes [see Milly, 1993; RodriguezIturbe and Porporato, 2004; Porporato et al., 2004; Settin et al., 2007]: (1) stochastic instantaneous increments due to infiltration from rainfall; (2) linear losses due to evapotranspiration increasing from 0 at the wilting point, $s_{w}$, up to the maximum evapotranspiration rate, $E T$, at a suitable soil moisture threshold, $s_{1}$; (3) instantaneous deep percolation producing effective rainfall and subsurface contributions to streamflow (above the threshold $s_{1}$ ).

[9] In this framework, subsurface events are assumed to be triggered by the exceedance of the soil moisture threshold $s_{1}$ (which is typically between field capacity and soil saturation). The effective rainfall pulses infiltrating beyond the root zone are assumed to propagate through deeper soil layers as subsurface flow [Eng and Milly, 2007] and eventually be released to the channel network as subsurface flow. Consequently, the temporal evolution of subsurface 


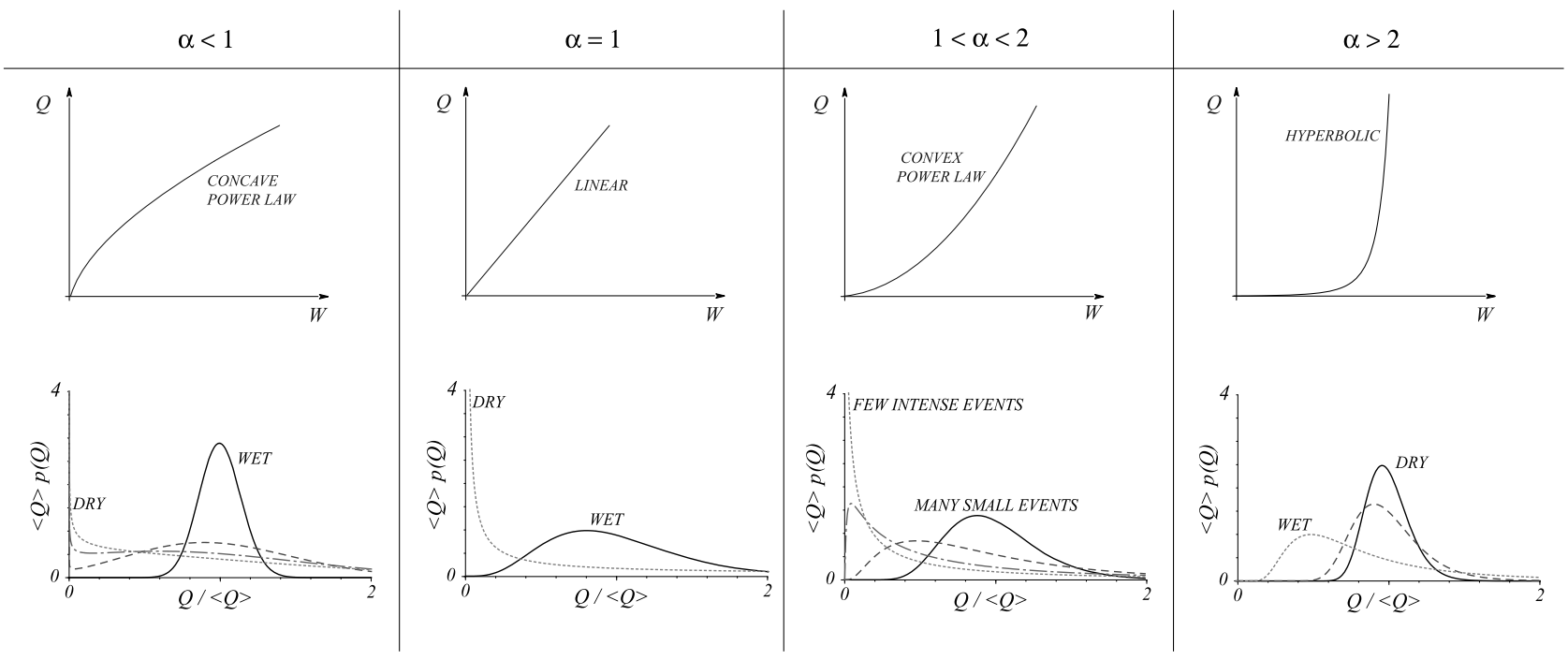

Figure 1. Summary of storage-discharge relationships and related possible shapes of $p(Q)$ (redrawn from Botter et al. [2009]). See text for a detailed comment.

contribution to streamflows, $Q$, is made up of two processes: (1) stochastic instantaneous jumps, in correspondence to each effective rainfall event described as marked Poisson process; and (2) deterministic decays between subsequent events.

[10] Assuming that the deeper soil regions receiving the water pulses percolating from the near-surface root zone behave, in the most general condition, as nonlinear reservoir (i.e., $Q=\rho(W), \rho$ being a nonlinear function of the storage $W$ ) [e.g., Amorocho and Orlob, 1961; Brutsaert and Nieber, 1977; Wittenberg, 1999; Porporato and Ridolfi, 2003; Kirchner, 2009], the temporal decay of streamflow through time between effective rainfall events is described by the following relation:

$$
\frac{d Q(t)}{d t}=-k Q(t)^{\alpha}+\xi_{t}
$$

where $\xi_{t}$ represents the stochastic noise (the jumps of $Q$ in correspondence of the fraction of rainfall events producing streamflow); $\alpha$ and $k\left[L^{1-\alpha} T^{\alpha-2}\right]$ are constants. In particular, the exponent $\alpha$ determines the rate of decrease of $Q$ during the recession. Here we focus on three different nonlinear behaviors between storage and discharge (concave power law model, $\alpha<1$; convex power law model, $1<\alpha<2$; hyperbolic model, $\alpha>2$ ), which are described in detail below. Hence the general expression of the steady state probability distribution function of streamflows is the following [Botter et al., 2009]:

$$
\begin{aligned}
p(Q)= & C\left\{\frac{1}{Q^{\alpha}} \exp \left[-\frac{\gamma_{W}}{k(2-\alpha)} Q^{2-\alpha}+\frac{\lambda}{k(1-\alpha)} Q^{1-\alpha}\right]\right. \\
& \left.+\frac{k}{\lambda} \delta(Q) H[1-\alpha]\right\},
\end{aligned}
$$

where $C$ is the normalizing constant, $H$ is the Heaviside unit step function, $\gamma_{W}=\gamma_{P} / A\left[L^{-1}\right]$ represents the inverse of the mean storage increment due to incoming rainfall events, and $\lambda\left[T^{-1}\right]$ represents the average frequency of effective rainfall (i.e., runoff) events. Following equation $(2), p(Q)$ is given by the sum of a continuous part of the probability density function of $Q$, common for all cases, and an atom of probability in $Q=0$, associated to the Dirac delta function and emerging only in the concave power law model.

[11] Figure 1 summarizes the possible shapes of the streamflow pdf as a function of the type of storagedischarge relation used, here described by the type of recession exhibited by the discharge through the value assumed by the exponent $\alpha$. When $\alpha<1$ (concave power law model), there exists an atom of probability in $Q=0$ and the pdf monotonically decreases with no inflection points. A single inflection point is observed when the climatic conditions are dry, or else the pdf is bell-shaped under wet climatic conditions. When $\alpha=1$, the linear model applies and the resulting pdf is bell shaped when $\lambda / k>1$ (termed "wet" conditions because no ephemeral flows are observed via a nonzero probability of zero discharge), while for $\lambda / k<1$ ("dry" conditions) $p(Q)$ goes to infinity for $Q \rightarrow 0$, and monotonically decreases for $Q>0$. When $1<\alpha<2$ (convex power law model), $p(Q)$ is always bell-shaped and its mode can be arbitrarily close to zero or to the mean of the distribution, depending on whether few intense rainfall events or many smaller ones, respectively, contribute to the seasonal climate. Finally, when $\alpha>2$ (hyperbolic model) the streamflow pdf always remains bell-shaped. Under dry climatic conditions $p(Q)$ appears to be nearly symmetrical and characterized by a low streamflow variability with respect to the mean value of the distribution, while for wet conditions it appears notably right-skewed.

[12] It should be noted that the models employed do not account directly for fast streamflow components unrelated to storage-discharge relations. In many cases of interest, and in particular at daily timescale in catchments devoid of extended impermeable surfaces, such fast components correspond to surface flows triggered by intense storms and are usually significantly exceeded by the subsurface component [Botter et al., 2007c]. Therefore the slight underestimation of the probability of the largest streamflow values possibly emerging in this framework will be disregarded. Care will also be exerted in the choice of hydrologic regimes, owing 
Table 1. Summary of the Key Geographical and Hydrologic Features for the 13 Catchments Considered in This Paper ${ }^{\mathrm{a}}$

\begin{tabular}{|c|c|c|c|c|c|c|c|}
\hline Catchment & Coordinates & $A,\left(\mathrm{~km}^{2}\right)$ & Period & Season & $\begin{array}{c}\gamma_{P} \\
\left(\mathrm{~cm}^{-1}\right)\end{array}$ & $\begin{array}{c}\lambda_{P} \\
\left(\mathrm{~d}^{-1}\right)\end{array}$ & $\begin{array}{c}\langle Q\rangle, \\
(\mathrm{cm} / \mathrm{d})\end{array}$ \\
\hline Boite Creek at Cancia (IT) & $46^{\circ} 25^{\prime} 50^{\prime \prime} \mathrm{N} 12^{\circ} 13^{\prime} 20^{\prime \prime} \mathrm{E}$ & 313.15 & $1986-2008$ & Summer (June-August) & 1.53 & 0.65 & 0.29 \\
\hline Boite Creek at Podestagno (IT) & $46^{\circ} 35^{\prime} 04^{\prime \prime} \mathrm{N} 12^{\circ} 06^{\prime} 31^{\prime \prime} \mathrm{E}$ & 82.38 & 1992-2008 & Summer (June-August) & 1.24 & 0.56 & 0.30 \\
\hline Cordevole River at La Vizza (IT) & $46^{\circ} 13^{\prime} 06^{\prime \prime} \mathrm{N} 11^{\circ} 50^{\prime} 04^{\prime \prime} \mathrm{E}$ & 7.79 & 1984-2008 & Summer (June-August) & 1.17 & 0.55 & 0.38 \\
\hline Cordevole River at Saviner (IT) & $46^{\circ} 26^{\prime} 31^{\prime \prime} \mathrm{N} 11^{\circ} 59^{\prime} 13^{\prime \prime} \mathrm{E}$ & 109.26 & 1990-2008 & Summer (June-August) & 1.39 & 0.63 & 0.23 \\
\hline Fiorentina River at Sottorovei (IT) & $46^{\circ} 26^{\prime} 21^{\prime \prime} \mathrm{N} 12^{\circ} 00^{\prime} 40^{\prime \prime} \mathrm{E}$ & 58.16 & 1993-2008 & Summer (June-August) & 1.23 & 0.57 & 0.22 \\
\hline Padola Creek at S. Stefano di Cadore (IT) & $46^{\circ} 33^{\prime} 30^{\prime \prime} \mathrm{N} 12^{\circ} 32^{\prime} 52^{\prime \prime} \mathrm{E}$ & 130.37 & 1986-2007 & Summer (June-August) & 1.21 & 0.58 & 0.26 \\
\hline Piave River at Ponte della Lasta (IT) & $46^{\circ} 32^{\prime} 11^{\prime \prime} \mathrm{N} 12^{\circ} 31^{\prime} 17^{\prime \prime} \mathrm{E}$ & 354.99 & 1989-2006 & Summer (June-August) & 1.32 & 0.65 & 0.25 \\
\hline Sonna Creek at Feltre (IT) & $46^{\circ} 00^{\prime} 39^{\prime \prime} \mathrm{N} 11^{\circ} 54^{\prime} 48^{\prime \prime} \mathrm{E}$ & 119.61 & 1985-2007 & Summer (June-August) & 1.15 & 0.52 & 0.19 \\
\hline Bear Butte Creek at Deadwood (SD) & $44^{\circ} 20^{\prime} 08^{\prime \prime} \mathrm{N} 103^{\circ} 38^{\prime} 06^{\prime \prime} \mathrm{W}$ & 42.99 & 1988-2006 & Spring (March-May) & 1.07 & 0.30 & 0.09 \\
\hline Jacob Fork at Ramsey (NC) & $35^{\circ} 35^{\prime} 26^{\prime \prime} \mathrm{N} 81^{\circ} 34^{\prime} 01^{\prime \prime} \mathrm{W}$ & 66.56 & 1975-1994 & Spring (March-May) & 0.94 & 0.33 & 0.26 \\
\hline Redgate Creek at Columbus (TX) & 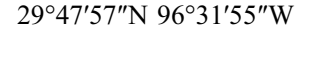 & 44.81 & $1987-2006$ & $\begin{array}{c}\text { Late Fall } \\
\text { (October-December) }\end{array}$ & 0.86 & 0.29 & 0.04 \\
\hline Rock Creek at Cedarville (WA) & $46^{\circ} 52^{\prime} 05^{\prime \prime} \mathrm{N} 123^{\circ} 18^{\prime} 25^{\prime \prime} \mathrm{W}$ & 64.23 & 1945-1971 & Summer (June-August) & 1.98 & 0.28 & 0.03 \\
\hline Rock Creek at Cedarville (WA) & $46^{\circ} 52^{\prime} 05^{\prime \prime} \mathrm{N} 123^{\circ} 18^{\prime} 25^{\prime \prime} \mathrm{W}$ & 64.23 & 1945-1971 & Winter (December-February) & 0.84 & 0.65 & 0.79 \\
\hline West Swan River at Silica (MN) & $47^{\circ} 17^{\prime} 36^{\prime \prime} \mathrm{N} 93^{\circ} 02^{\prime} 30^{\prime \prime} \mathrm{E}$ & 42.22 & 1963-1979 & Summer (June-August) & 1.17 & 0.34 & 0.04 \\
\hline
\end{tabular}

${ }^{a}$ Coordinates of catchment closure section; drainage area, $A$; period of observation of streamflows; considered season; inverse of the mean daily rainfall depth, $\gamma_{P}$; mean rainfall frequency, $\lambda_{P}$; mean observed streamflow, $\langle Q\rangle$.

to the need of selecting basins/seasons examined unaffected by inferences due to snow accumulation/melting.

[13] The variability observed in the shape of the streamflow pdf depending on the degree of nonlinearity between storage and discharge in subsurface environments is also reflected in the flow duration curve of a river basin. The flow duration curve is a mathematical function associating to each possible discharge $Q$ the percentage of time during which such discharge is equaled or exceeded during a given time interval (e.g., during one year) [Vogel and Fennessey, 1994]. From a mathematical viewpoint, the flow duration curve $D(Q)$ is expressed as the probability of exceeding $Q$ during a given reference period:

$$
D(Q)=\int_{Q}^{\infty} p(x) d x
$$

where substitution of equation (2) into (3) allows for exact expressions of the flow duration curves.

\subsection{Study Catchments and Hydrologic Data}

[14] Catchments unaffected by snowmelting and anthropogenic regulation are considered. The selected catchments are located in northeastern Italy and in the United States and cover a wide range of climatic and geomorphic conditions. They have already been considered for comparison between the observed pdf of daily streamflows and the theoretical Gamma distribution derived for the linear case, in several past studies. Streamflow and rainfall statistics have been derived by continuous daily streamflow and rainfall measurements collected, for the Italian basin, by the environmental regional agency ARPAV, and for the U.S. basins by the U.S. Geological Survey (http://waterdata.usgs.gov). Table 1 reports the foremost features of the 13 study catchments investigated. The reader interested in further details is referred to Botter et al. [2007c, 2008, 2010].

\subsection{Parameter Estimation}

[15] The characterization of the probability distribution function of streamflows for a river basin given by equation (2) relies on the specification of four model parameters (i.e., $\alpha, k$,
$\gamma_{W}, \lambda$ ) which can be estimated in a relatively simple manner from basic hydrologic and geomorphologic information as follows.

[16] The parameters $\alpha$ and $k$, describing the deterministic decay of streamflow through time between subsequent effective rainfall events (equation (1)), can be directly derived from daily streamflow measurements, analyzing the recession curves. Following Brutsaert and Nieber [1977], the rate of flow recession is estimated by plotting the temporal derivative of $Q(-d Q / d t)$, estimated as the difference in streamflow between two successive days, $-d Q / d t=\left(Q_{t-\Delta t}-\right.$ $\left.Q_{t}\right) / \Delta t$, versus the corresponding average value of $Q$ over two days, $\left(Q_{t-\Delta t}+Q_{t}\right) / 2$. Because $Q$ and $-d Q / d t$ will both typically span several orders of magnitude, their mutual relation is best viewed on log-log plots. Owing to random measurement noise and, overall, to the randomness in the underlying climatic and transport processes, the observed data show significant scatter, particularly at low discharges [Kirchner, 2009]. This can involve a biased estimate of $k$ and $\alpha$, and for these reasons, we have assessed the value of these two parameters for the study catchments of this paper through the following four methods:

[17] 1. Method 1 (M1) is linear least squares regression of $\log (-d Q / d t)$ plotted versus the corresponding observed values of $\log (Q)$ (Figure $2 \mathrm{a}$ ).

[18] 2. Method $2(\mathrm{M} 2)$ is linear least squares regression of average $\log (-d Q / d t)$ plotted versus the corresponding average observed values of $\log (Q)$. This is done by binning the individual daily data points into ranges of $Q$, having the same extent, $\Delta Q$ (Figure $2 \mathrm{~b}$ ).

[19] 3. Method 3 (M3) is least squares regression of average $\log (-d Q / d t)$ plotted versus the corresponding average observed values of $\log (Q)$. This is done by binning the individual daily data points into ranges of $Q$, having the same logarithmic extent, $\log (\Delta Q)$ (Figure 2c).

[20] 4. Method 4 (M4) is nonlinear least squares interpolation of the estimated temporal derivative of $Q(d Q / d t)$ plotted versus the corresponding observed values of $Q$, finding the optimum $k$ and $\alpha$ directly from equation (1) (Figure 2d).

[21] For methods M1, M2, and M3, $\alpha$ represents the log$\log$ slope of the best fit line, while $\log (k)$ is the intercept. For 

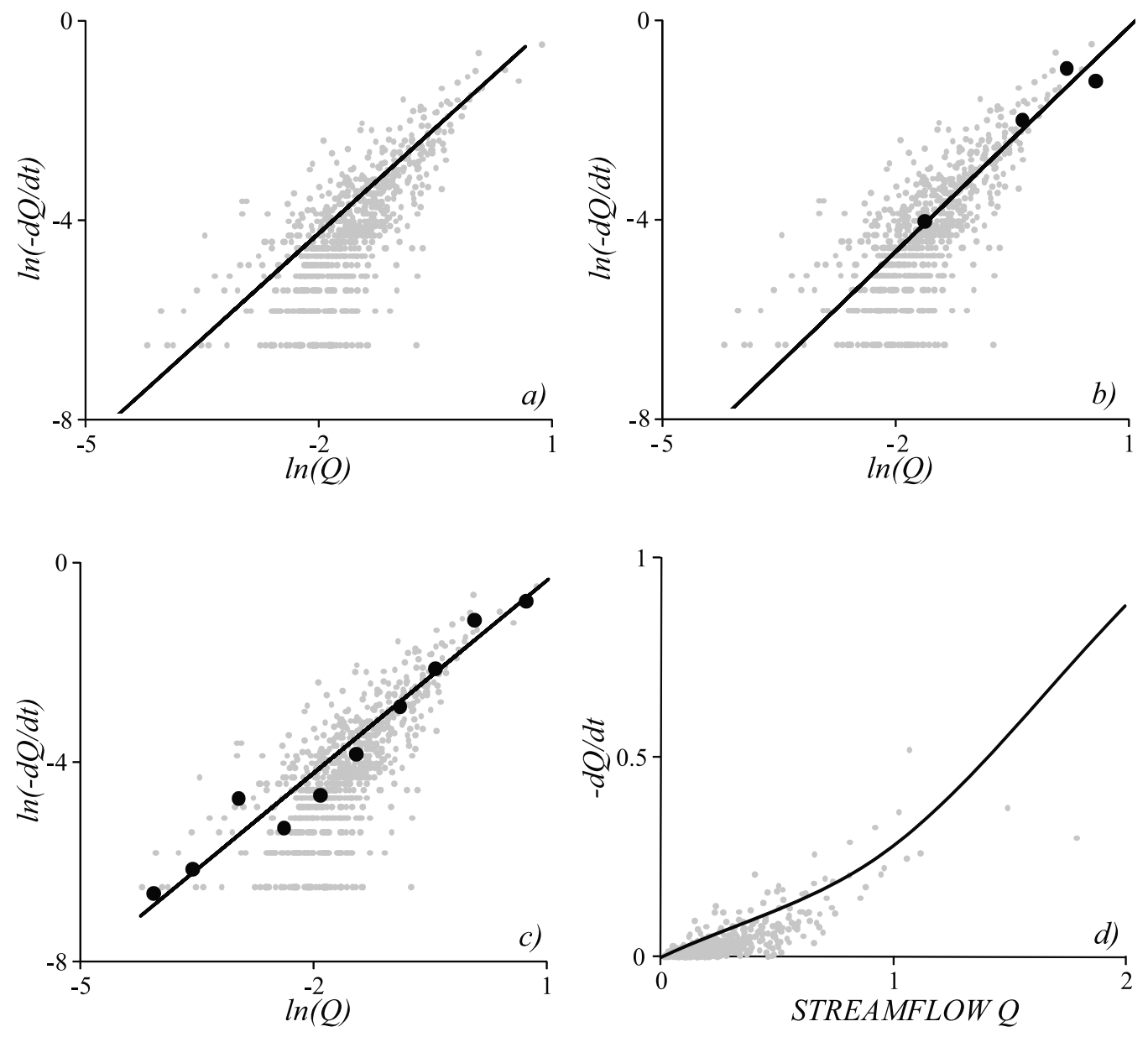

Figure 2. Estimate of $k$ and $\alpha$. (a) M1, recession log-log plot with flow recession rates (individual daily data, gray dots) and regression line (solid line); (b) M2, recession log-log plot with flow recession rates (individual daily data, gray dots; normal binned data, black dots) and regression line (solid line); (c) M3, recession log-log plot with flow recession rates (individual daily data, gray dots; logarithmic binned data, black dots) and regression line (solid line); (d) M4, recession plot with flow recession rates (individual daily data, gray dots) and regression curve (solid line). The plots refer to Fiorentina Creek at Sottorovei (see Table 1). Streamflows units are in $\mathrm{cm} / \mathrm{day}$. Units for $d Q / d t$ are $\mathrm{cm} / \mathrm{day}^{2}$.

these three methods, we have defined the confidence intervals of the parameter estimates. In the linear case $\alpha=1$, the parameter $k$ (which represents the inverse of the mean response time in subsurface states, or equivalently the inverse of the recession time constant of the hydrograph) is computed from streamflow measurements as in M4 by a linear regression. As the linear regression was found to reasonably approximate the experimental points for low and medium values of $Q$, the regression has been applied only to the data smaller than the 90th percentile of the observed distribution.

[22] The determination of both the parameters $\gamma_{W}$ and $\lambda$, instead, is based on the preliminary determination of the parameters defining the probabilistic structure of rainfall, $\lambda_{P}$ and $\gamma_{P}$. The latter two parameters are not fitted but are derived from pluviometric information gathered in a number of meteorological stations located within or nearby the considered catchment. Daily rainfall data recorded in various stations are first averaged to estimate the temporal evolution of spatially averaged rainfall rates. Then, the average frequency of rainfall events, $\lambda_{P}$, is derived by comparing the probability distribution of the number of wet days in a reference time period with the corresponding Poisson pdf assumed by the rainfall model. Similarly, the inverse of the mean rainfall depths during wet days, $\gamma_{P}$, is derived by comparing the observed distribution of spatially averaged daily depths during wet days with the exponential distribution assumed by the model. On this basis, the parameter $\gamma_{W}$ can be easily calculated from the values of the parameters $\gamma_{P}$ and $A$, according to the definition given in section 2.1 . Finally, the estimate of the frequency of effective rainfall events, $\lambda$, requires specific care and is performed in three different ways:

[23] 1. The first way (W1) is directly from streamflow data, by simply counting the frequency of positive jumps observed in the time series available (i.e. $Q_{t+1}>Q_{t}$ ).

[24] 2. The second way (W2) is directly from streamflow and rainfall data, by performing a mass balance in the subsurface states under the root zone between the mean inflow $\lambda / \gamma_{P}$ and the mean outflow $\langle Q\rangle$.

[25] 3. The third way (W3) is indirectly from the crossing properties of the threshold $s_{1}$ and in terms of the underlying 
Table 2. Parameters of the Analytical Model for the 13 Study Catchments Considered in This Paper ${ }^{\mathrm{a}}$

\begin{tabular}{|c|c|c|c|c|c|c|c|c|}
\hline Catchment & Season & $\gamma_{W}\left(\mathrm{~cm}^{-1}\right)$ & $\lambda\left(\mathrm{d}^{-1}\right)$ & Method & $\mathrm{k}\left(\mathrm{cm}^{1-\alpha} \mathrm{d}^{2-\alpha}\right)$ & $\alpha$ & K-S Test & $\mathrm{AIC}$ \\
\hline \multirow[t]{5}{*}{ Boite Creek at Cancia (IT) } & \multirow{5}{*}{$\begin{array}{c}\text { Summer } \\
\text { (June-August) }\end{array}$} & \multirow[t]{5}{*}{1.53} & \multirow[t]{5}{*}{0.45} & M1 & $0.14 \pm 0.02$ & $1.91 \pm 0.10$ & 0.089 & -251.11 \\
\hline & & & & M2 & $0.23 \pm 0.02$ & $2.02 \pm 0.12$ & 0.033 & -309.96 \\
\hline & & & & M3 & $0.22 \pm 0.08$ & $1.79 \pm 0.06$ & 0.030 & -311.10 \\
\hline & & & & M4 & 0.22 & 2.02 & 0.036 & -305.48 \\
\hline & & & & linear & 0.07 & 1 & 0.062 & -268.24 \\
\hline \multirow{5}{*}{$\begin{array}{l}\text { Boite Creek at } \\
\text { Podestagno (IT) }\end{array}$} & \multirow{5}{*}{$\begin{array}{c}\text { Summer } \\
\text { (June-August) }\end{array}$} & \multirow[t]{5}{*}{1.24} & \multirow[t]{5}{*}{0.38} & M1 & $0.23 \pm 0.02$ & $2.03 \pm 0.07$ & 0.134 & -234.61 \\
\hline & & & & M2 & $0.25 \pm 0.02$ & $1.92 \pm 0.11$ & 0.091 & -254.94 \\
\hline & & & & M3 & $0.25 \pm 0.03$ & $1.90 \pm 0.10$ & 0.091 & -254.91 \\
\hline & & & & M4 & 0.26 & 1.82 & 0.068 & -264.00 \\
\hline & & & & linear & 0.1 & 1 & 0.091 & -237.47 \\
\hline \multirow{5}{*}{$\begin{array}{l}\text { Cordevole River at } \\
\text { La Vizza (IT) }\end{array}$} & \multirow{5}{*}{$\begin{array}{c}\text { Summer } \\
\text { (June-August) }\end{array}$} & \multirow[t]{5}{*}{1.17} & \multirow[t]{5}{*}{0.44} & M1 & $0.11 \pm 0.01$ & $1.12 \pm 0.06$ & 0.140 & -230.82 \\
\hline & & & & M2 & $0.18 \pm 0.03$ & $1.57 \pm 0.20$ & 0.134 & -230.58 \\
\hline & & & & M3 & $0.20 \pm 0.03$ & $1.75 \pm 0.13$ & 0.150 & -222.02 \\
\hline & & & & M4 & 0.17 & 1.64 & 0.154 & -221.98 \\
\hline & & & & linear & 0.12 & 1 & 0.105 & -245.27 \\
\hline Cordevole River at & Summer & 1.39 & 0.33 & M1 & $0.09 \pm 0.01$ & $1.26 \pm 0.08$ & 0.100 & -254.15 \\
\hline Saviner (IT) & (June-August) & & & M2 & $0.21 \pm 0.03$ & $1.73 \pm 0.16$ & 0.068 & -271.08 \\
\hline & & & & M3 & $0.22 \pm 0.07$ & $1.64 \pm 0.17$ & 0.043 & -290.29 \\
\hline & & & & M4 & 0.21 & 1.82 & 0.086 & -257.66 \\
\hline & & & & linear & 0.08 & 1 & 0.083 & -259.33 \\
\hline Fiorentina River at & Summer & 1.23 & 0.27 & M1 & $0.13 \pm 0.02$ & $1.40 \pm 0.08$ & 0.095 & -253.78 \\
\hline Sottorovei (IT) & (June-August) & & & M2 & $0.22 \pm 0.09$ & $1.50 \pm 0.45$ & 0.058 & -259.35 \\
\hline & & & & M3 & $0.19 \pm 0.08$ & $1.29 \pm 0.17$ & 0.060 & -233.88 \\
\hline & & & & M4 & 0.23 & 1.66 & 0.062 & -278.32 \\
\hline & & & & linear & 0.10 & 1 & 0.093 & -236.66 \\
\hline Padola Creek at S. Stefano & Summer & 1.21 & 0.31 & M1 & $0.08 \pm 0.01$ & $1.39 \pm 0.10$ & 0.105 & -243.23 \\
\hline di Cadore (IT) & (June-August) & & & M2 & $0.22 \pm 0.04$ & $1.87 \pm 0.20$ & 0.042 & -264.36 \\
\hline & & & & M3 & $0.18 \pm 0.06$ & $1.79 \pm 0.24$ & 0.055 & -260.43 \\
\hline & & & & M4 & 0.22 & 2.11 & 0.089 & -241.85 \\
\hline & & & & linear & 0.07 & 1 & 0.074 & -255.57 \\
\hline Piave River at Ponte della & Summer & 1.32 & 0.33 & M1 & $0.26 \pm 0.05$ & $2.21 \pm 0.12$ & 0.048 & -278.72 \\
\hline Lasta (IT) & (June-August) & & & M2 & $0.26 \pm 0.09$ & $1.82 \pm 0.41$ & 0.087 & -239.88 \\
\hline & & & & M3 & $0.34 \pm 0.03$ & $2.17 \pm 0.08$ & 0.038 & -276.36 \\
\hline & & & & M4 & 0.24 & 1.69 & 0.111 & -227.78 \\
\hline & & & & linear & 0.07 & 1 & 0.081 & -227.89 \\
\hline Sonna Creek at Feltre (IT) & Summer & 1.15 & 0.22 & M1 & $0.13 \pm 0.03$ & $1.71 \pm 0.11$ & 0.052 & -282.17 \\
\hline & (June-August) & & & M2 & $0.28 \pm 0.08$ & $1.96 \pm 0.31$ & 0.080 & -259.06 \\
\hline & & & & M3 & $0.35 \pm 0.10$ & $2.06 \pm 0.18$ & 0.085 & -256.16 \\
\hline & & & & M4 & 0.28 & 1.91 & 0.095 & -250.14 \\
\hline & & & & linear & 0.06 & 1 & 0.092 & -232.59 \\
\hline Bear Butte Creek at & Spring & 1.07 & 0.10 & M1 & $0.09 \pm 0.01$ & $0.90 \pm 0.04$ & 0.079 & -281.16 \\
\hline Deadwood (SD) & (March-May) & & & M2 & $0.27 \pm 0.15$ & $1.28 \pm 0.38$ & 0.032 & -312.00 \\
\hline & & & & M3 & $0.29 \pm 0.08$ & $1.36 \pm 0.08$ & 0.065 & -323.33 \\
\hline & & & & M4 & 0.23 & 1.19 & 0.059 & -293.23 \\
\hline & & & & linear & 0.16 & 1 & 0.121 & -275.31 \\
\hline Jacob Fork at Ramsey (NC) & Spring & 0.94 & 0.25 & M1 & $0.30 \pm 0.03$ & $1.86 \pm 0.05$ & 0.099 & -275.26 \\
\hline & (March-May) & & & M2 & $0.38 \pm 0.04$ & $1.56 \pm 0.10$ & 0.094 & -271.67 \\
\hline & & & & M3 & $0.34 \pm 0.07$ & $1.70 \pm 0.13$ & 0.060 & -311.46 \\
\hline & & & & M4 & 0.39 & 1.51 & 0.121 & -257.85 \\
\hline & & & & linear & 0.07 & 1 & 0.170 & -246.19 \\
\hline Redgate Creek at & Late Fall & 0.86 & 0.04 & M1 & $0.43 \pm 0.04$ & $1.10 \pm 0.02$ & 0.087 & -531.43 \\
\hline Columbus (TX) & (October-December) & & & M2 & $0.59 \pm 0.19$ & $1.11 \pm 0.10$ & 0.062 & -506.78 \\
\hline & & & & M3 & $0.54 \pm 0.32$ & $0.97 \pm 0.31$ & 0.049 & -521.98 \\
\hline & & & & M4 & 0.72 & 0.91 & 0.065 & -497.64 \\
\hline & & & & linear & 0.80 & 1 & 0.054 & -504.04 \\
\hline Rock Creek at & Summer & 1.98 & 0.06 & M1 & $0.07 \pm 0.01$ & $0.86 \pm 0.03$ & 0.254 & -195.08 \\
\hline Cedarville (WA) & (June-August) & & & M2 & $0.37 \pm 0.05$ & $1.40 \pm 0.07$ & 0.137 & -216.69 \\
\hline & & & & M3 & $0.31 \pm 0.05$ & $1.38 \pm 0.05$ & 0.107 & -224.81 \\
\hline & & & & M4 & 0.35 & 1.45 & 0.074 & -224.14 \\
\hline & & & & linear & 0.08 & 1 & 0.167 & -217.65 \\
\hline Rock Creek at & Winter & 0.84 & 0.66 & M1 & $0.16 \pm 0.01$ & $1.56 \pm 0.03$ & 0.239 & -200.61 \\
\hline Cedarville (WA) & (December-February) & & & M2 & $0.19 \pm 0.01$ & $1.53 \pm 0.07$ & 0.211 & -208.61 \\
\hline & & & & M3 & $0.18 \pm 0.01$ & $1.55 \pm 0.02$ & 0.218 & -206.43 \\
\hline & & & & M4 & 0.18 & 1.53 & 0.213 & -207.76 \\
\hline & & & & linear & 0.27 & 1 & 0.110 & -248.23 \\
\hline
\end{tabular}


Table 2. (continued)

\begin{tabular}{|c|c|c|c|c|c|c|c|c|}
\hline Catchment & Season & $\gamma_{W}\left(\mathrm{~cm}^{-1}\right)$ & $\lambda\left(\mathrm{d}^{-1}\right)$ & Method & $\mathrm{k}\left(\mathrm{cm}^{1-\alpha} \mathrm{d}^{2-\alpha}\right)$ & $\alpha$ & K-S Test & AIC \\
\hline \multirow{5}{*}{$\begin{array}{l}\text { West Swan River at } \\
\text { Silica (MN) }\end{array}$} & Summer & 1.17 & 0.04 & M1 & $0.21 \pm 0.02$ & $0.95 \pm 0.03$ & 0.409 & -243.49 \\
\hline & (June-August) & & & M2 & $0.42 \pm 0.09$ & $1.15 \pm 0.13$ & 0.363 & -248.65 \\
\hline & & & & M3 & $0.42 \pm 0.08$ & $1.18 \pm 0.05$ & 0.323 & -248.79 \\
\hline & & & & M4 & 0.43 & 1.20 & 0.306 & -247.87 \\
\hline & & & & linear & 0.48 & 1 & 0.567 & -232.30 \\
\hline
\end{tabular}

anverse of the mean storage increment, $\gamma_{W}$; mean effective rainfall frequency, $\lambda$ (W2 estimate); coefficients of temporal decay of $Q$ (equation (1)), $k$ and $\alpha$, derived according to the following methods (see text): M1, M2, M3, M4, linear (in italics); results of the K-S test carried out on the observed pdfs and the analytical ones (the best results, characterized by the lowest $\mathrm{K}-\mathrm{S}$ value, are shown in bold); the last column reports the Akaike Information Criterion (AIC) used as a tool for model identification.

soil, vegetation and rainfall parameters properly fixed $\left(s_{1}-s_{w}, E T, n Z_{r}\right)$ via:

$$
\lambda=\eta \frac{\exp \left(-\gamma_{S}\right) \gamma_{S}^{\frac{\lambda_{P}}{\eta}}}{\Gamma\left(\lambda_{P} / \eta, \gamma_{S}\right)}
$$

where $\Gamma(a, b)$ is the lower incomplete gamma function of parameters $a$ and $b, \eta=E T /\left(n Z_{r}\left(s_{1}-s_{w}\right)\right)$ is the normalized maximum evapotranspiration rate and $\gamma_{S}=\gamma_{P} n Z_{r}\left(s_{1}-s_{w}\right)$ is the ratio between the soil storage capacity and the mean rainfall depth. In particular, the difference between $s_{1}$ and $s_{w}$, which depends on soil and vegetation characteristics, can be reasonably estimated from rough land cover and soil type information [e.g., Rodriguez-Iturbe and Porporato, 2004], while the effective soil depth can be determined by exploiting soil and geopedologic information. Finally, the maximum evapotranspiration rate $E T$ can be calculated on the basis of land cover and climatic data via standard soil-atmosphere interaction models (e.g., Penman-Monteith). According to this last method, as $E T$ decreases, $\lambda$ increases and the pdf of streamflows shows a greater mode with a lower peak.

\section{Results and Discussion}

[26] To test the ability of nonlinear models to reproduce the statistics of the streamflows observed and to verify the robustness of the procedure for the parameter identification, the analytical streamflow pdf given by equation (2) is compared with the seasonal streamflow pdfs observed in the 13 catchments listed in Table 1. A parallel comparison is also carried out with the linear version of the model. The analysis also considers the related flow duration curves.

[27] The complete set of the model parameters for the catchments considered in this paper is reported in Table 2. With reference to the different estimation procedures for $\lambda, k$ and $\alpha$, a Kolmogorov-Smirnov test has been performed to compare the various methods and assess the most suitable one.

[28] The best value of $\lambda$ is provided by W2 for all basins, even though also the method W1 performs reasonably good in most cases. This was somehow expected because the W2 method matches by definition the mean of the streamflow distribution. W3 proves to be the less accurate method. This is likely due to the high number of parameters that need to be estimated. Therefore we have decided to report in Table 2 only the result obtained with the W2 method. For what concerns the estimate of $k$ and $\alpha$, Table 2 reports the values obtained by the four methods. The best outcome for each basin is properly highlighted using bold text. The best values of $k$ and $\alpha$ are provided by M3 method in 5 out of
14 cases (best performance with respect to all other methods). Hence we show here the $p(Q)$ and the $D(Q)$ plots only for this method.

[29] For brevity, we report here only the results of the comparison between modeled and observed streamflow statistics (i.e., $p(Q)$ and $D(Q)$ ) in the following basins: Boite Creek at Cancia, Cordevole River at Saviner and Fiorentina Creek at Sottorovei for the Piave River catchment, and Rock Creek (WA), Redgate Creek (TX), and West Swan River (MN) for the U.S. basins, which summarize all the observed hydrologic regimes and climatic conditions. Results obtained for the remaining basins are reported in the auxiliary material. $^{1}$

[30] Figure 3a shows the graphical comparison of observed (circles), nonlinear analytical (solid line) and linear analytical (dashed line) daily streamflows pdfs during the summer period (June-August) for the Boite Creek closed at Cancia. The plot suggests that the version of the model which includes the effects of nonlinear storage-discharge relation allows for an increase in the model accuracy with respect to the linear scheme, in particular for the reproduction of mode of the distribution and the intermediate values of streamflow $(0.1<Q<0.6 \mathrm{~cm} / \mathrm{d})$. Figure $3 \mathrm{~d}$ shows the behavior of the long term flow duration curve for this basin, where the analytical solutions (nonlinear as a solid line, linear as a dashed line) are compared with the observed flow duration curves. Each empirical flow duration curve has been evaluated by means of a nonparametric approach (Weibull plotting position). The plot shows that the nonlinear model reproduces better than the linear scheme the behavior of the observed flow duration curve. Indeed, the nonlinear model represents remarkably well the durations for the whole set of discharges, while the linear model slightly underestimates the durations of the smallest and highest streamflows.

[31] In Figure 3b the same comparisons shown in Figure 3a are reported for the Cordevole River closed at Saviner. The summer (June-August) streamflow pdf shows a satisfactory agreement with the theoretical pdfs. In particular, the version of the model based on a nonlinear behavior of deeper soil layers points out a better reproduction of the distribution peak compared to the linear approach, which tends to slightly underestimate it. Figure 3e reports the observed and theoretical flow duration curves for the period 1990-2008. The results of the comparison between modeled and observed streamflow statistics for the summer period (June-August) in the Fiorentina Creek catchment closed at Sottorovei are also

\footnotetext{
${ }^{1}$ Auxiliary materials are available in the HTML. doi:101029/ 2010WR009102.
} 

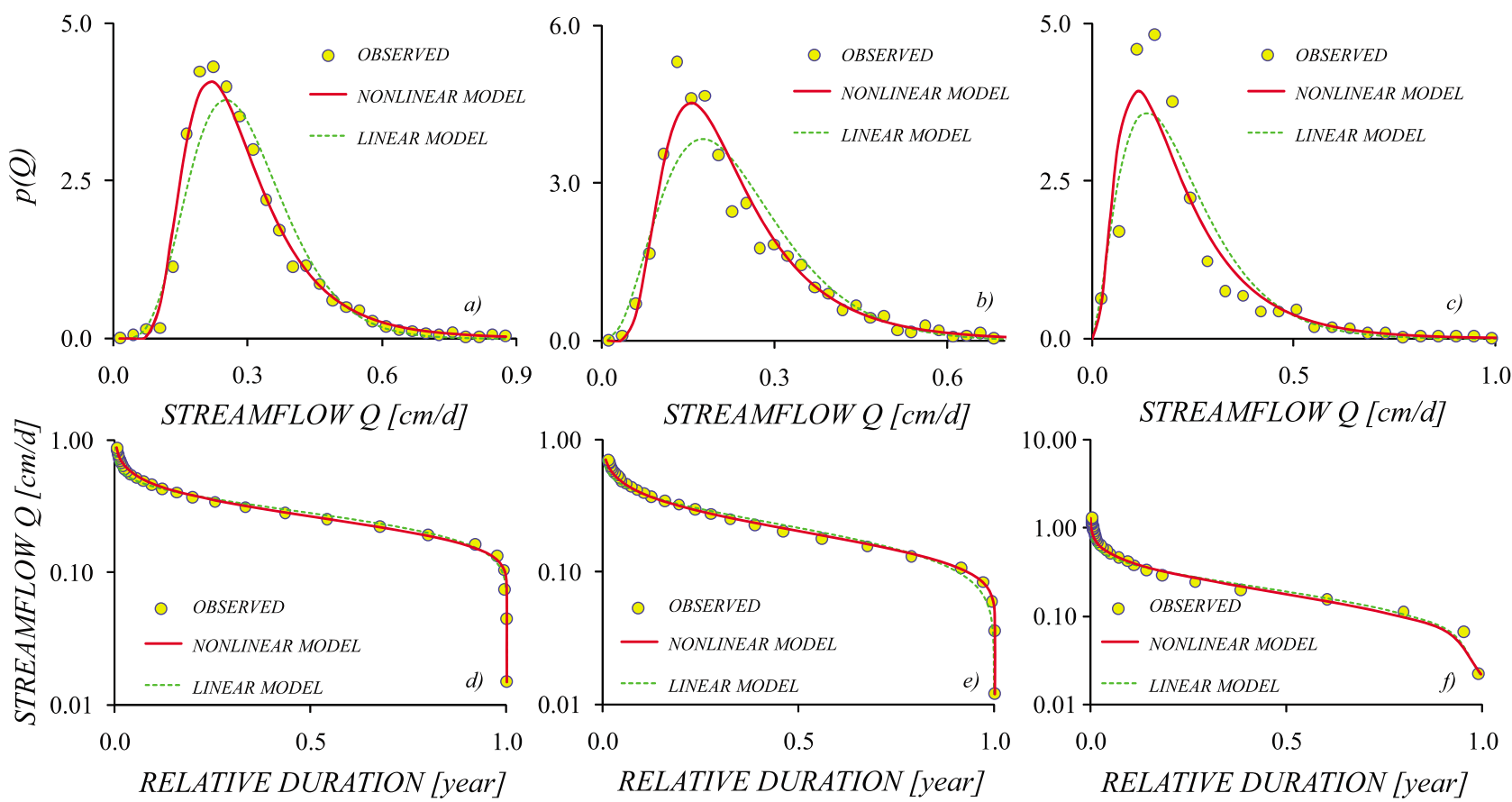

Figure 3. Streamflow statistics: comparison between nonlinear analytical (solid line), linear analytical (dashed line), and observed streamflow pdf (circles) in (a) Boite Creek at Cancia, (b) Cordevole River at Saviner, and (c) Fiorentina Creek at Sottorovei; comparison between nonlinear analytical (solid line), linear analytical (dashed line) and observed flow duration curves (circles) in a semilog plot in (d) Boite Creek at Cancia, (e) Cordevole River at Saviner, and (f) Fiorentina Creek at Sottorovei. Streamflows units are in $\mathrm{cm} /$ day.
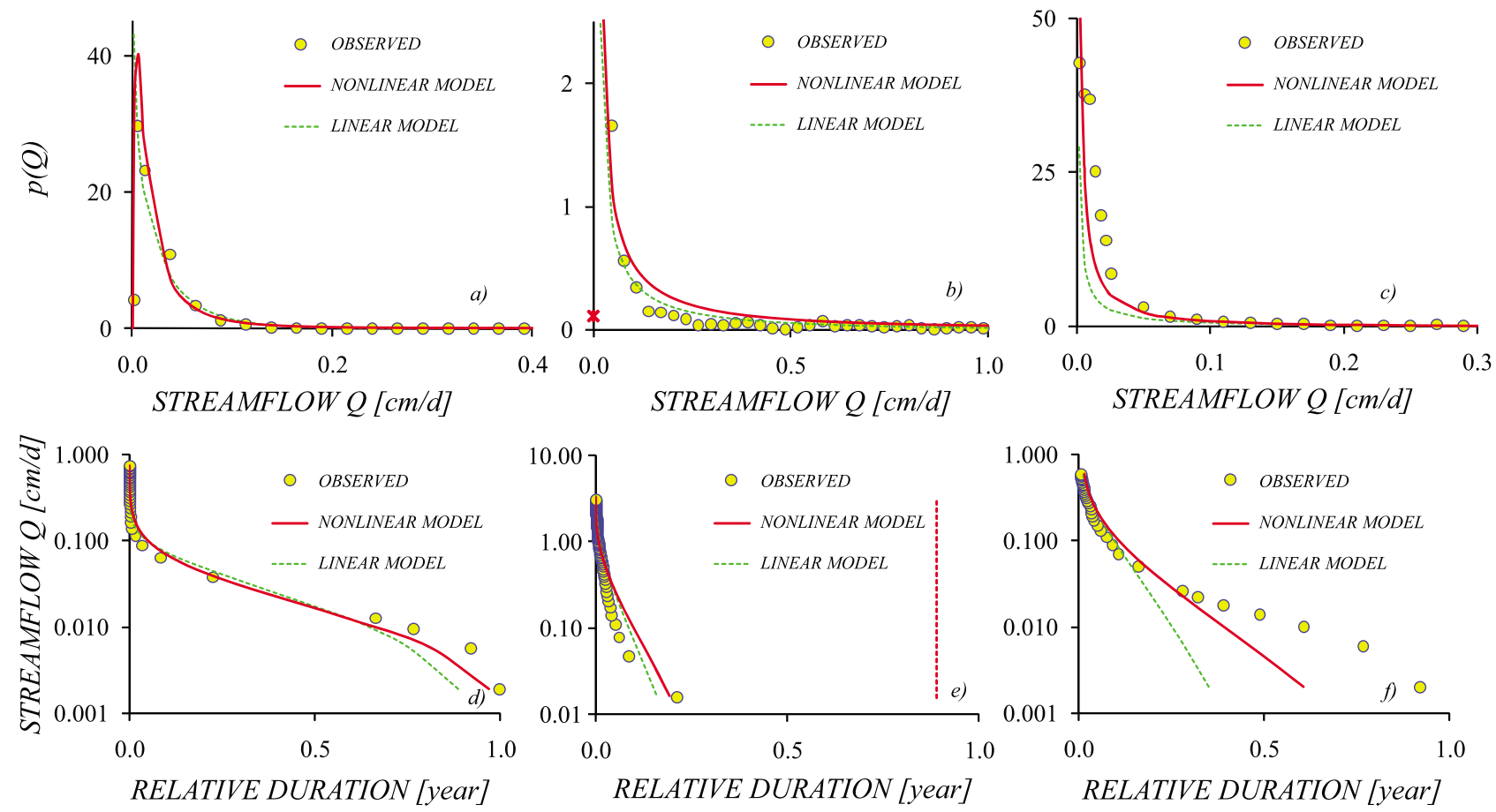

Figure 4. Streamflow statistics: comparison between nonlinear analytical (solid line), linear analytical (dashed line) and observed streamflow pdf (circles) in (a) Rock Creek (WA), (b) Redgate Creek (TX), and (c) West Swan River (MN); comparison between nonlinear analytical (solid line), linear analytical (dashed line), and observed flow duration curves (circles) in a semilog plot in (d) Rock Creek (WA), (e) Redgate Creek (TX), and (f) West Swan River (MN). Streamflows units are in cm/day. 
Table 3. Hydrologic Characterization From Observed $p(Q)^{\mathrm{a}}$

\begin{tabular}{|c|c|c|c|c|c|c|c|}
\hline Catchment & Season & $\gamma_{W}\left(\mathrm{~cm}^{-1}\right)$ & $\lambda\left(\mathrm{d}^{-1}\right)$ & Method & $\mathrm{k}\left(\mathrm{cm}^{1-\alpha} \mathrm{d}^{2-\alpha}\right)$ & $\alpha$ & K-S Test \\
\hline \multirow{2}{*}{ Boite Creek at Cancia (IT) } & \multirow{2}{*}{ Summer (June-August) } & \multirow[t]{2}{*}{1.53} & \multirow{2}{*}{0.45} & LS & 0.29 & 2.08 & 0.008 \\
\hline & & & & MLE & 0.20 & 1.76 & 0.021 \\
\hline \multirow[t]{2}{*}{ Boite Creek at Podestagno (IT) } & \multirow[t]{2}{*}{ Summer (June-August) } & \multirow[t]{2}{*}{1.24} & \multirow[t]{2}{*}{0.38} & LS & 0.69 & 2.38 & 0.034 \\
\hline & & & & MLE & 0.57 & 2.32 & 0.031 \\
\hline \multirow[t]{2}{*}{ Cordevole River at La Vizza (IT) } & \multirow[t]{2}{*}{ Summer (June-August) } & \multirow[t]{2}{*}{1.17} & \multirow[t]{2}{*}{0.44} & LS & 0.44 & 1.77 & 0.023 \\
\hline & & & & MLE & 0.40 & 1.81 & 0.022 \\
\hline \multirow[t]{2}{*}{ Cordevole River at Saviner (IT) } & \multirow[t]{2}{*}{ Summer (June-August) } & \multirow[t]{2}{*}{1.39} & \multirow[t]{2}{*}{0.33} & LS & 0.39 & 1.93 & 0.022 \\
\hline & & & & MLE & 0.29 & 1.73 & 0.024 \\
\hline \multirow[t]{2}{*}{ Fiorentina River at Sottorovei (IT) } & \multirow[t]{2}{*}{ Summer (June-August) } & \multirow[t]{2}{*}{1.23} & \multirow[t]{2}{*}{0.27} & LS & 0.35 & 1.87 & 0.039 \\
\hline & & & & MLE & 0.21 & 1.39 & 0.054 \\
\hline \multirow[t]{2}{*}{ Padola Creek at S. Stefano di Cadore (IT) } & \multirow[t]{2}{*}{ Summer (June-August) } & \multirow[t]{2}{*}{1.21} & \multirow[t]{2}{*}{0.31} & LS & 0.22 & 1.74 & 0.030 \\
\hline & & & & MLE & 0.20 & 1.70 & 0.032 \\
\hline \multirow[t]{2}{*}{ Piave River at Ponte della Lasta (IT) } & \multirow[t]{2}{*}{ Summer (June-August) } & \multirow[t]{2}{*}{1.32} & \multirow[t]{2}{*}{0.33} & LS & 0.48 & 2.50 & 0.014 \\
\hline & & & & MLE & 0.57 & 2.64 & 0.021 \\
\hline \multirow[t]{2}{*}{ Sonna Creek at Feltre (IT) } & \multirow[t]{2}{*}{ Summer (June-August) } & \multirow[t]{2}{*}{1.15} & 0.22 & LS & 0.24 & 2.05 & 0.032 \\
\hline & & & & MLE & 0.27 & 2.08 & 0.028 \\
\hline Bear Butte Creek at Deadwood (SD) & Spring (March-May) & 1.07 & 0.10 & LS & 0.69 & 1.57 & 0.049 \\
\hline & & & & MLE & 0.44 & 1.44 & 0.029 \\
\hline Jacob Fork at Ramsey (NC) & Spring (March-May) & 0.94 & 0.25 & LS & 0.87 & 2.20 & 0.038 \\
\hline & & & & MLE & 0.89 & 2.30 & 0.027 \\
\hline Redgate Creek at Columbus (TX) & Late Fall (October-December) & 0.86 & 0.04 & LS & 1.20 & 1.91 & 0.390 \\
\hline & & & & MLE & 6.85 & 2.03 & 0.051 \\
\hline Rock Creek at Cedarville (WA) & Summer (June-August) & 1.98 & 0.06 & LS & 1.20 & 1.78 & 0.066 \\
\hline & & & & MLE & 0.30 & 1.51 & 0.032 \\
\hline Rock Creek at Cedarville (WA) & Winter (December-February) & 0.84 & 0.66 & LS & 0.75 & 2.03 & 0.090 \\
\hline & & & & MLE & 0.52 & 1.54 & 0.022 \\
\hline West Swan River at Silica (MN) & Summer (June-August) & 1.17 & 0.04 & LS & 0.35 & 1.45 & 0.097 \\
\hline & & & & MLE & 0.87 & 1.65 & 0.051 \\
\hline
\end{tabular}

${ }^{\mathrm{a}}$ For each catchment we report the following parameters: inverse of the mean storage increment, $\gamma_{W}$; mean effective rainfall frequency, $\lambda$ (here reported only W2's estimate); coefficients of temporal decay of $Q$ (equation (1)), $k$ and $\alpha$, estimated using (1) the least squares method (LS) and (2) the maximum likelihood estimator method (MLE). The last column provides the results of K-S test performed between the observed pdfs and the analytical ones. The best results (characterized by lower K-S value) are reported in bold.

shown in Figures $3 \mathrm{c}$ and $3 \mathrm{f}$. Indeed, the nonlinear model reproduces quite well the streamflow pdf for all values of $Q$, while the linear scheme tends to underestimate the peak of the probability distribution. In all the considered cases the modeled pdfs correspond to a wet climate regime (Figure 1), a feature also shown by experimental data.

[32] Figure 4a shows the comparison between the predicted and the observed streamflow pdfs for the summer period (June-August) in the Rock Creek catchment in Washington. The observed data shows that the mode of the probability distribution is close to $Q=0$. While the linear model shows an unsuitable behavior as $p(Q) \rightarrow \infty$ for $Q \rightarrow 0$, the nonlinear model is able to reproduce remarkably well this behavior, even though the peak of the distribution is slightly overestimated. The analytical pdf (solid line) exhibits a mode corresponding to a climate regime characterized by few intense rainfall events. The analytical and observed flow duration curves for the period 1945-1971 reported in Figure $4 \mathrm{~d}$ resemble those of Figure $4 \mathrm{a}$. Results of the comparison between modeled and observed streamflow statistics for the late fall period (October-December) in the Redgate Creek catchment in Texas are shown in Figures $4 \mathrm{~b}$ and $4 \mathrm{e}$. Both the linear and nonlinear versions of the analytical model allow a good reproduction of the observed streamflow statistics. The nonlinear version of the model, however, is able to reproduce the observed atom of probability in $Q=0$ (Figure 4b). The observed flow duration curve shows a duration smaller than 1 . Thus the Redgate Creek regime can be considered ephemeral and typical of semiarid regions. The analytical models are able to reproduce the behavior of the observed flow duration curves only for the largest streamflows.

[33] Figures 4c and 4f show the same analysis for the West Swan River catchment in Minnesota (June-August). The plot suggests that the nonlinear version of the model can reproduce the behavior of the observed flow duration curve significantly better than the linear scheme, even though the durations corresponding to the smallest streamflow values are underestimated. The smallest discharges seem to be most sensitive to the nonlinearity of the recession curves owing to the relatively dry climate conditions characterizing the area.

[34] Overall, the comparisons evidence the effectiveness of both linear and nonlinear models to reproduce the major features of the observed streamflows in rather different catchments. However, in most cases the nonlinear model allows an improved reproduction of the observed streamflow statistics with respect to the linear approach. To assess whether the addition of a new parameter in the nonlinear model is justified by an increment of likelihood we use the Akaike's Information Criterion (AIC, Table 2, last column) [Akaike, 1974; Burnham and Anderson, 2002], which allows the comparison of alternative models discounting the effects of different numbers of parameters. The lowest AIC figure, regardless of its actual value, identifies the best model. Indeed, AIC values suggest that in 12 out of 14 cases the nonlinear model fits better the data, and in the large majority of cases the minimum AIC matches the optimal identification from the $\mathrm{K}-\mathrm{S}$ test for the nonlinear model. When it does not match, differences are indeed very small both in the parameter values and the AIC. Other techniques, 

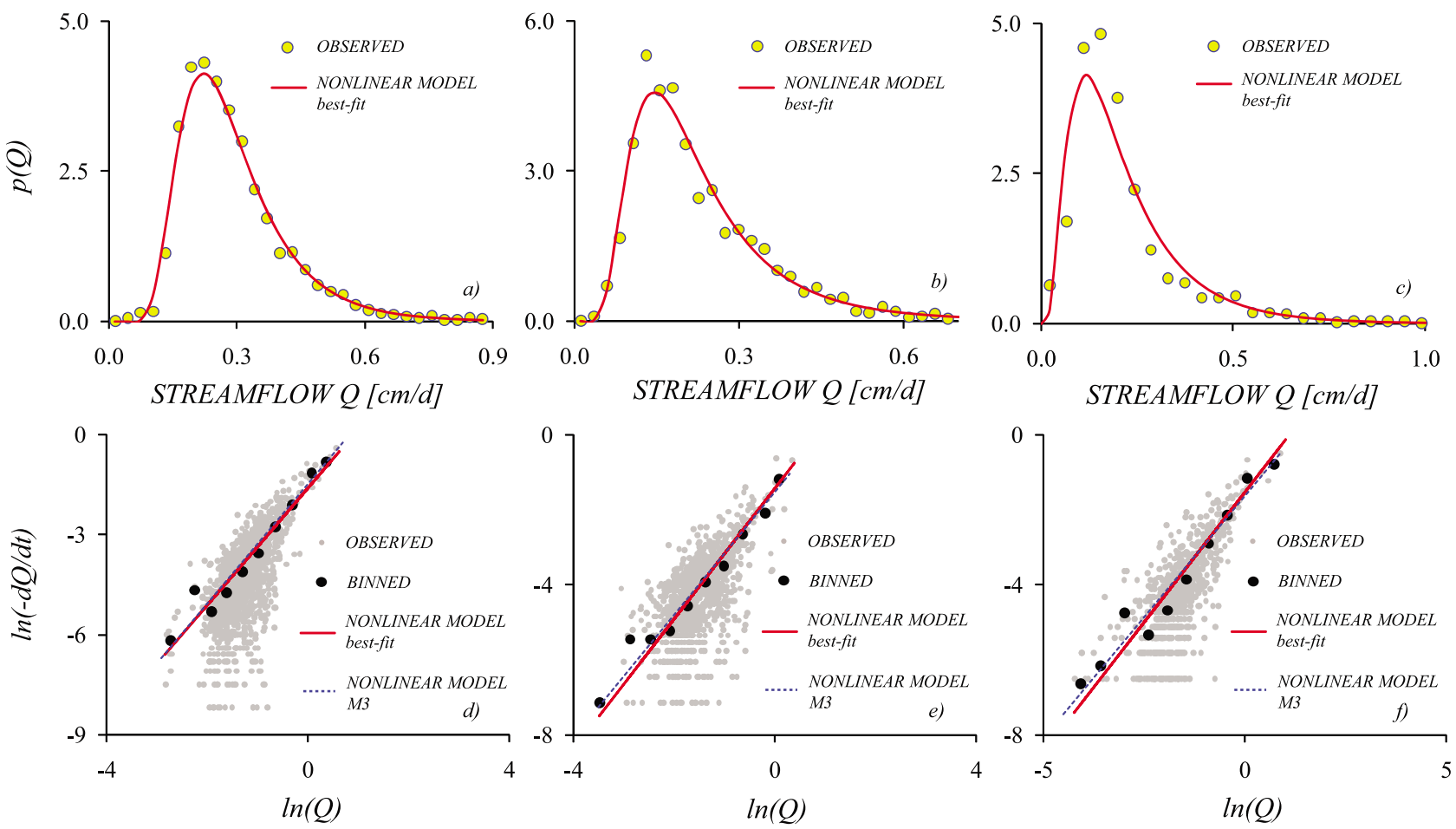

Figure 5. Inference of nonlinear behavior from observed $p(Q)$ : comparison between nonlinear analytical streamflow pdf derived through a best-fit procedure (solid line) and observed streamflow pdf (circles) in (a) Boite Creek at Cancia, (b) Cordevole River at Saviner, and (c) Fiorentina Creek at Sottorovei; comparison between observed flow recession rates (individual daily data, gray dots; binned data, black dots), recession trend derived through best-fit procedure (solid line) and recession trend described by M3 method (dashed line) in (d) Boite Creek at Cancia, (e) Cordevole River at Saviner, and (f) Fiorentina Creek at Sottorovei. Streamflows units are in $\mathrm{cm} /$ day.

like, e.g., the Bayesian Information Criterion (BIC) not reported herein for brevity, confirm the AIC figures. We thus conclude that the added parameter is truly significant confirming that the nonlinear storage-discharge relation closely describes the catchment behavior. Note that in two cases (Cordevole River at La Vizza, Rock Creek at Cedarville, winter season) the linear model is clearly identified from both the $\mathrm{K}-\mathrm{S}$ procedure and the AIC.

[35] Until now, for the application of the model presented in section 2.1, the parameters $k$ and $\alpha$, describing the nonlinearities between $Q$ and $W$, have been derived from flow recession curves by interpolation of the observed values of $d Q / d t$ versus $Q$. The approach, however, also suggests an alternative procedure to infer possible nonlinearities in the storage-discharge relations, starting from the streamflow pdf. The tenet is grounded on the idea that the values of $k$ and $\alpha$ may be calibrated by performing a best-fit procedure on the observed whole probability distribution function of $Q$ to the analytical expression (equation (2)). This procedure requires a preliminary and independent estimate of the remaining parameters of the streamflow distribution, $\gamma_{W}$ and $\lambda$, from hydrologic data. The fitting procedure can be conveniently carried out by using (1) the least squares (LS) method or (2) the maximum likelihood estimator (MLE) method, and the ensuing parameter values are reported in Table 3. A Kolmogorov-Smirnov test has been performed to compare these two methods. Figures 5 and 6 show the $p(Q)$ and the log-log recession plots for the same catchments reported in Figures 3 and 4.
[36] For the Boite Creek catchment closed at Cancia, $k$ and $\alpha$ estimates provided by the best-fit procedure let an excellent agreement between the observed and the analytical $p(Q)$ (Figure 5a). These values, reported in the recession plot (Figure 5d (solid line)), describe remarkably well the observed behavior of the catchment during recession phases (gray dots), and show a trend almost indistinguishable from that of the recession curve analysis (dashed line, method M3). The same applies to Cordevole River at Saviner and Fiorentina Creek at Sottorovei (Figures 5b, 5c, 5e, and 5f).

[37] Figure 6 shows the results of the same analysis for the U.S. catchments considered herein. For the Rock Creek (WA) (Figures 6a and 6d) $k$ and $\alpha$ values derived using the best-fit procedure provide a good agreement between the observed and the analytical $p(Q)$, even though the peak of the distribution is slightly overestimated. The estimated values provide a good representation of the actual trend of $-d Q / d t$ versus $Q$ (Figure $6 \mathrm{~d}$ ), although in this case recession curve analysis parameters (method M3) seem to describe in a better way the nonlinear behavior. For the Redgate Creek (TX), however, the pdf obtained using the best-fit procedure reproduces well the observed data only for $Q>0$ (the analytical pdf is bell-shaped with the mode close to zero, whereas the data do not show such behavior, see Figure 6b). The recession plot (Figure 6e) reflects this feature, as the observed data are not well represented by the parameters obtained from the best-fit procedure. Analogously, the West Swan River (MN) shows a good general fit of the observed pdf of streamflows, though the observed data do not display 

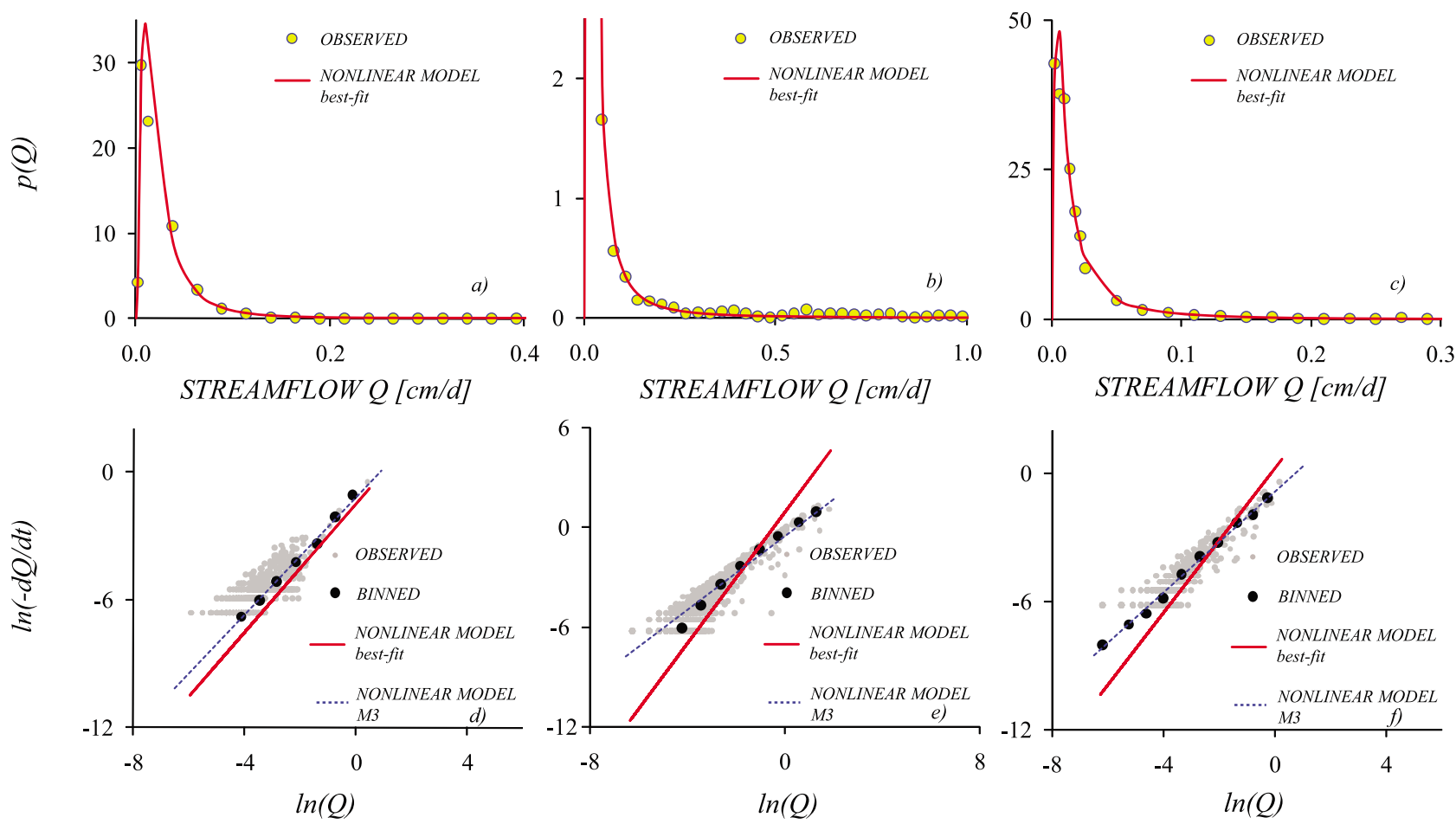

Figure 6. Inference of nonlinear behavior from observed $p(Q)$ : comparison between nonlinear analytical streamflow pdf derived through a best-fit procedure (solid line) and observed streamflow pdf (circles) in (a) Rock Creek (WA), (b) Redgate Creek (TX), and (c) West Swan River (MN); comparison between observed flow recession rates (individual daily data, gray dots; binned data, black dots), recession trend derived through best-fit procedure (solid line) and recession trend described by M3 method (dashed line) in (d) Rock Creek (WA), (e) Redgate Creek (TX), and (f) West Swan River (MN). Streamflows units are in $\mathrm{cm} /$ day.

the bell-shaped trend evidenced in the analytical $p(Q)$ (Figure 6c). Also in this case the coefficients of equation (1), defined using the best-fit procedure, tend to slightly overestimate the observed recession behavior. The poor performance of the latter two cases is likely due to an incorrect estimate of $\lambda$. In fact the best-fit procedure depends on independent estimates of the physically meaningful parameters $\gamma_{W}$ and $\lambda$ (equation (2)). While the estimate of $\gamma_{W}$ from data is straightforward, a reliable determination of the frequency of effective rainfall events $\lambda$ requires specific attention, as previously discussed in relation to the different estimate procedures (i.e., W1, W2, W3).

[38] It should be noted that for most examined cases (see also auxiliary material) the best-fit procedure gives better estimates of $k$ and $\alpha$ than those provided by the recession curve analysis, which is affected by considerable uncertainty induced by the noisy measurements of recession rates, the numerical approximation and the binning intervals used to estimate the temporal derivatives of $d Q / d t$, and by the type of the interpolation employed. Calibrating $k$ and $\alpha$ from entire streamflow pdfs, instead, would possibly provide an estimate of the effective value assumed by such parameters during a given season, integrating the fluctuations frequently observed in the hydrologic behavior of a catchment in a straightforward manner.

\section{Conclusions}

[39] The following conclusions are worth mentioning.
[40] 1. Seasonal probability distribution functions of daily streamflows (and their derived flow duration curves), computed from data gathered in different catchments (in northeastern Italy and the United States), have been compared to physically based analytical distributions. The parameters have been estimated from rainfall, hydrologic, climatic, and land use information, suggesting the possible prediction of hydrologic variability on the basis of a few parameters endowed with clear physical meaning and often directly measurable. Indeed the coefficients describing mathematically the decay of $Q$ in time between subsequent runoff events $(k$ and $\alpha$ ) have been derived from empirical recession plots (using four different statistical techniques), while the calibration of effective rainfall frequency $(\lambda)$ has been carried out (by three different approaches) facing field data.

[41] 2. The general agreement between predicted and observed daily streamflows pdfs and flow duration curves is satisfactory in all cases investigated, with different degrees of adaptation depending on the context. The version of the model which includes the effects of nonlinear storagedischarge relation allows for a generalized, significant increase in the predictive power of theoretical tools, say by broadening the range of streamflows for which the model can be reliably applied. The predictive power of the analytical tools has been emphasized.

[42] 3. A byproduct of the proposed analysis is a new procedure to characterize catchment-scale storage-discharge relations (and, consequently, the temporal decay of $Q$ between subsequent effective rainfall events). The procedure 
consists of fitting whole streamflow pdfs through the estimation of the storage-discharge parameters ( $k$ and $\alpha$ ) from observed streamflows using suitable statistical tools. This approach provides an estimate of the effective value assumed by such parameters during a given season, filtering the fluctuations unavoidable in the hydrologic behavior of a catchment in a straightforward and inclusive manner. The method requires a preliminary, uncoupled estimate of the parameters characterizing the pdf that are directly measurable from data as that hold a clear physical meaning.

[43] We thus conclude that the general theoretical approach to the probabilistic structure of streamflows that we seek to validate reproduces a wide range of hydrologic conditions, and bears the advantages of analytical solutions. This supports its applicability to many cases of practical interest, in particular for feasibility assessment of management options and ecosystem preservation planning, toward a quantitative definition of ecologically favorable flow regimes in relations to biodiversity conservation.

[44] Acknowledgments. This research is supported by funds provided by ERC advanced grant RINEC 22761 and SFN funding through the project 200021_124930/1. The writers wish to thank Lorenzo Mari, Laboratory of Ecohydrology ECHO/IEE/ENAC at EPFL, for advice in model identification techniques.

\section{References}

Akaike, H. (1974), A new look at the statistical model identification, IEEE Trans. Aut. Control, 19(6), 716-723.

Amorocho, J. (1963), Measures of the linearity of hydrologic systems, J. Geophys. Res., 68(8), 2237-2249.

Amorocho, J. (1967), The nonlinear prediction problem in the study of the runoff cycle, Water Resour. Res., 3(3), 861-880.

Amorocho, J., and G. T. Orlob (1961), Nonlinear analysis of hydrologic systems, Contrib. 60, 154 pp., Water Resour. Cent., Univ. of Calif., Los Angeles.

Beven, K. (2001), Rainfall-Runoff Modelling: The Primer, Wiley, Chichester, U. K.

Botter, G., A. Porporato, I. Rodriguez-Iturbe, and A. Rinaldo (2007a), Basin-scale soil moisture dynamics and the probabilistic characterization of carrier hydrologic flows: Slow, leaching-prone components of the hydrologic response, Water Resour. Res., 43, W02417, doi:10.1029/ 2006WR005043.

Botter, G., A. Porporato, E. Daly, I. Rodriguez-Iturbe, and A. Rinaldo (2007b), Probabilistic characterization of base flows in river basins: Roles of soil, vegetation and geomorphology, Water Resour. Res., 43, W06404, doi:10.1029/2006WR005397.

Botter, G., F. Peratoner, A. Porporato, I. Rodriguez-Iturbe, and A. Rinaldo (2007c), Signatures of large-scale soil moisture dynamics on streamflow statistics across U.S. climate regimes, Water Resour. Res., 43, W11413, doi:10.1029/2007WR006162.

Botter, G., S. Zanardo, A. Porporato, I. Rodriguez-Iturbe, and A. Rinaldo (2008), Ecohydrological model of flow duration curves and annual minima, Water Resour. Res., 44, W08418, doi:10.1029/2008WR006814.

Botter, G., A. Porporato, I. Rodriguez-Iturbe, and A. Rinaldo (2009), Nonlinear storage-discharge relations and catchment streamflow regimes, Water Resour. Res., 45, W10427, doi:10.1029/2008WR007658.

Botter, G., S. Basso, A. Porporato, I. Rodriguez-Iturbe, and A. Rinaldo (2010), Natural streamflow regime alterations: Damming of the Piave river basin (Italy), Water Resour. Res., 46, W06522, doi:10.1029/ 2009WR008523.

Brutsaert, W. (2005), Hydrology: An Introduction, Cambridge Univ. Press, New York.
Brutsaert, W., and J. P. Lopez (1998), Basin-scale geo-hydrologic drought flow features of riparian aquifers in the southern Great Plains, Water Resour. Res., 34(2), 233-240.

Brutsaert, W., and J. L. Nieber (1977), Regionalized drought flow hydrographs from a mature glaciated plateau, Water Resour. Res., 13(3), 637-648.

Burnham, K. P., and D. R. Anderson (2002), Model Selection and Multimodel Inference, 2nd ed., Springer, New York.

Chow, V. T. (1964), Handbook of Applied Hydrology, McGraw-Hill, New York.

Chow, V. T., D. R. Maidment, and L. W. Mays (1988), Applied Hydrology, McGraw-Hill, New York.

Eng, K., and P. C. D. Milly (2007), Relating low-flow characteristics to the base flow recession time constant at partial record stream gauges, Water Resour. Res., 43, W01201, doi:10.1029/2006WR005293.

Jothityangkoon, C., M. Sivapalan, and D. L. Farmer (2001), Process controls of water balance variability in a large semi-arid catchment: Downward approach to hydrological model development, J. Hydrol., 254, 174-198.

Kirchner, J. W. (2009), Catchments as simple dynamical systems: Catchment characterization, rainfall-runoff modeling, and doing hydrology backward, Water Resour. Res., 45, W02429, doi:10.1029/2008WR006912.

Lee, D. (2007), Testing a conceptual hillslope recession model based on the storage discharge relationship with the Richards equation, Hydrol. Processes, 21, 3155-3161, doi:10.1002/hyp.6537.

Magruder, I. A., W. W. Woessner, and S. W. Running (2009), Ecohydrologic process modeling of mountain block groundwater recharge, Ground Water, 47(6), 774-785.

Milly, P. C. D. (1993), An analytic solution of the stochastic storage problem applicable to soil-water, Water Resour. Res., 29(11), 3755-3758.

Mishra, A., H. Takeshi, W. Abdelhadi, A. Tada, and H. Tanakamaru (2003), Recession flow analysis of the Blue Nile River, Hydrol. Processes, 17, 2825-2835, doi:10.1002/hyp.1436.

Porporato, A., and L. Ridolfi (2003) Detecting determinism and nonlinearity in riverflow time series, Hydrol. Sci. J., 48(5), 763-780.

Porporato, A., E. Daly, and I. Rodriguez-Iturbe (2004), Soil water balance and ecosystem response to climate change, Am. Nat., 164(5), 625-632.

Rinaldo, A., A. Marani, and R. Rigon (1991) Geomorphological dispersion, Water Resour. Res., 27(4), 513-525.

Rocha, D., J. Feyen, and A. Dassargues (2007), Comparative analysis between analytical approximations and numerical solutions describing recession flow in unconfined hillslope aquifers, Hydrogeol. J., 15, 1077-1091, doi:10.1007/s10040-007-0170-4.

Rodriguez-Iturbe, I., and A. Porporato (2004), Ecohydrology of Water Controlled Ecosystems: Soil Moisture and Plant Dynamics, Cambridge Univ. Press, New York.

Rodriguez-Iturbe, I., and A. Rinaldo (1997), Fractal River Basins: Chance and Self-Organization, Cambridge Univ. Press, New York.

Rodriguez-Iturbe, I., A. Porporato, L. Ridolfi, V. Isham, and D. Cox (1999), Probabilistic modelling of water balance at a point: The role of climate soil and vegetation, Proc. R. Soc. London, Ser. A, 455, 3789-3805.

Settin, T., G. Botter, I. Rodriguez-Iturbe, and A. Rinaldo (2007), Numerical studies on soil moisture distributions in heterogeneous catchments, Water Resour. Res., 43, W05425, doi:10.1029/2006WR005737.

Van de Griend, A. A., J. J. De Vries, and E. Seyhan (2002), Groundwater discharge from areas with a variable specific drainage resistance, J. Hydrol., 259, 203-220.

Vogel, R. M., and N. M. Fennessey (1994), Flow-duration. I: New interpretation and confidence intervals, J. Water Resour. Plan. Manage., 120(4), 485-504.

Wittenberg, H. (1999), Baseflow recession and recharge as nonlinear storage processes, Hydrol. Processes, 13, 715-726.

E. Bertuzzo, S. Ceola, and A. Rinaldo, Laboratory of Ecohydrology ECHO/IEE/ENAC, Faculté ENAC, Ecole Polytechnique Fédérale, CH-1015 Lausanne, Switzerland. (andrea.rinaldo@epfl.ch)

G. Botter, Dipartimento di Ingegneria Idraulica, Marittima, Ambientale e Geotecnica, Università di Padova, I-35122 Padova, Italy.

A. Porporato, Department of Civil and Environmental Engineering, Duke University, Durham, NC 27708, USA.

I. Rodriguez-Iturbe, Department of Civil and Environmental Engineering, Princeton University, Engineering Quad, Princeton, NJ 08544, USA. 